\title{
Erratum to: Removal of Some Radionuclides Using Stannic Silicovanadate as Inorganic Ion Exchanger
}

\author{
Y. F. El-Aryan ${ }^{a, b}$, E. A. Abdel-Galil ${ }^{a, *}$, and N. Belacy $a$ \\ a Atomic Energy Authority, Hot Labs. Centre, P. No. 13759, Egypt \\ *e-mail:mabdelamid@yahoo.com \\ ${ }^{b}$ Chemistry Department, Faculty of Sciences, University of Bisha, Bisha, Saudi Arabia
}

Received December 7, 2018

DOI: $10.1134 / \mathrm{S} 1070427218100245$

In affiliation section, line 3, "Bisha University" should be replaced by "University of Bisha."

The original article can be found online at https://doi.org/10.1134/S1070427218090185 